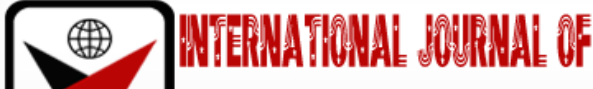

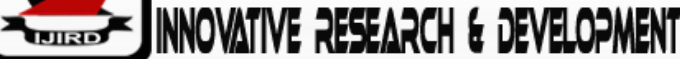

ISSN 2278 - 0211 (Online)

\section{The Impact of Financial Technology in the Operations (Payments/Collections) of SMEs in Nigeria}

\author{
Godgift David, Ahmed-Ishmel \\ Postgraduate Student, Faculty of Management Sciences, University of Lagos, Nigeria \\ Charles Onyeiwu \\ Lecturer, Faculty of Management Sciences, University of Lagos, Nigeria \\ Obakayode Akinola Owopetu \\ Postgraduate Student, Faculty of Management Sciences, University of Lagos, Nigeria
}

\begin{abstract}
:
This study examines the impact of Financial Technology in the Operations (Payments/Collections) of SMEs in Nigeria. The study conducted a survey of 120 Small and Medium Scale Enterprises across the four (4) identified geo-political zones in Lagos state. These SMEs with employment ranging from 2-10 employees in the fashion, educational, online merchants, pharmaceuticals, automobile, cosmetics, agro-allied, printing, bakery, eatery, I.T. firms and retail enterprises. This was done in such a way that the four axes were represented, each axis having thirty (30) SMEs. One hundred (100) Questionnaires were found useful for the purpose of the study representing $83 \%$ of the total questionnaire distributed.

The data was analyzed using inferential statistics. The study reveals that Financial Technology (FinTech) has great impact on the economy, and therefore contributing positively to national development. It also discussed the benefits and risks of embracing and investing in FinTech. In order to remain sustainable and profitable in business in this 21st century, it was recommended that the financial authorities and government embark on massive campaign and support of emerging FinTech organizations as well as embracing FinTech in its operations. Also, the SMEs are highly recommended to adopt FinTech payment channels in their operations.
\end{abstract}

Keywords: E-Commerce, fintech, financial inclusion, financial education, game changer, startup, MFIs, technology hubs, Silicon Valley, venture capital, API

\section{Introduction}

Financial Technology (FinTech) refers to innovative financial services or products delivered via technology. With advancements in technology (such as mobile and internet communications) and their global adoption, consumers' expectations are changing. Many Small businesses, Startups and Medium Size companies are working on FinTech related products and this may have a disruptive effect on financial service channels.FinTech has also become a buzzword for small and innovative startup companies that develop Financial Technology and related products. This definition is useful in describing the dynamic world of start-up companies in the FinTech sector. However, it easily creates a picture in which the start-up becomes the main focal point, as opposed to the technology itself. In practice, Financial Technology is not the exclusive domain of the FinTechs as the more traditional banks, MFIs and Small and Medium Scale organizations make use of it as well.The recent rapid emergence of financial technology in the Nigeria Financial System and the Small and Medium Scale Enterprises have posed a continuous interest of stakeholders to enquire about the relevance of the adopted technologies. Some of the stakeholders are excited at the adoption considering the countless benefits experienced, such as ease and speed of operations in service delivery, while some are not, they are concerned about the associated and anticipated risks. This risk relates to the poor infrastructure and technical know-how of these technologies. Furthermore, Nigerians lack financial education which would have motivated users/customers to accept the innovative products and services that comes from technology.In focusing on the SMEs operations, the researchersare concerned about how much influence does Financial Technology has on SMEs. If a small business lacks any FinTech device, does it mean the business would be negatively affected? In other words, does the noise about the FinTech devices among SMEs affect the operations of the business? As FinTech gains a growing popularity in small business in Nigeria, it poses a deep concern about the requisite skill(s) to manage it in order to avoid loss of data and resources. The acceptance of FinTech is on a daily increase among business owners, a situation where a potential customer walks into a supermarket that accept only cash and the customer has his debit card, or a scenario where there is always a long 
queue at the cashier's point in a service organization as experienced in Lagos, this is a problem, would FinTech play a vital role at these scenarios? Objectives of the Study is to investigate the importance of Financial Technology and examine its adoption by small and medium scale enterprises in Nigeria and how it impacts their growth and impacts the Nigerian economy.

\section{Literature Review}

\subsection{Conceptual Framework}

In this section, the conceptual framework of FinTech as it relates to the SMEs and general service delivery, encompasses the features proposed by the researchers and reflect the perception of FinTech in the popular media, industrial reposts and scientific articles between the years 2012 and 2015. FinTech has three dimensions: an input (namely the combination of technology, organization and money flow), mechanisms (create or improve or change, disrupt, apply technology to finance, create competition on the market) and an output (creation of new services or products or processes or business models).

A closer look at the meaning of each of the aspects in the identified dimensions, the term "technologies", the definitions agree on the technologies which underlie financial services such as mobile payments, data analytics, crowd-based platforms or cryptocurrencies. Referring to the "organizations" the sources mean startups and companies, which focus their activities on providing IT-supported financial services or platforms. "Money flow" equals the investments, poured to support the development of such businesses. The dimension of mechanisms includes creation, change or improvement of existing service/product/process or business model in order to increase its quality for the customer (to make it transparent, accessible, to reduce costs or fees, etc.). These activities are supported by the use of technological advancements; this is reflected by the aspect of "application of IT to finance and service delivery". The disruptive function of FinTech is explained as the creation of alternatives to the existing services by financial institutions, for example, replacing bank as an intermediary. And finally, by doing so, FinTech creates competition not only among the startups working on the service, but also promote competition among businesses. The third, output dimension includes new services/ products/ processes/ business models, which emerge as the result of the transformation.

The thrust of this research work is on the second dimension "mechanism" a clear example its practice can be seen in the SMEs in Nigeria, they now have various means of payments/collections not only for their customers but for themselves. Hence, the need to understudy the impact on small and mediums scale businesses in Nigeria.

\subsection{Theoretical Framework}

Theories are formulated to explain, predict, and understand phenomena and, in many cases, to challenge and extend existing knowledge within the limits of critical bounding assumptions. It provides a generalized explanation to an occurrence. The theoretical framework is the structure that can hold or support a theory of a research study. It introduces and describes the theory that explains why the research problem under study exists. Therefore, a researcher should be conversant with those theories applicable to his area of research, Kombo and Tromp (2009) in order to be guided in analyzing and interpreting the data to be gathered. It also facilitates the understanding of concepts and variables according to given definitions and builds new knowledge by validating or challenging theoretical assumptions.

\subsection{Diffusion of Innovation Theory Rogers' (1995)}

Diffusion of Innovation (DOI) theory is a popular model used in information systems research to explain user adoption of new technologies. Rogers defines diffusion as 'the process by which an innovation is communicated through certain channels over time among the members of a social society' (Rogers, 1995). An innovation is an idea or object that is perceived to be new (Rogers, 1995). According to DOI, the rate of diffusion is affected by an innovation's relative advantage, complexity, compatibility, trialability and observability. Rogers (1995) defines relative advantage as 'the degree to which an innovation is seen as being superior to its predecessor'. Complexity, which is comparable to TAM's perceived ease of use construct, is 'the degree to which an innovation is seen by the potential adopter as being relatively difficult to use and understand'. Compatibility refers to 'the degree to which an innovation is seen to be compatible with existing values, beliefs, experiences and needs of adopters'. Trialability is the 'degree to which an idea can be experimented with on a limited basis'. Finally, observability is the 'degree to which the results of an innovation are visible' (Rogers, 1995). The diffusion theory is relevant because it explains the reason why banks adopt technical innovations. One of the reasons why banks adopt technical innovations is relevant advantage. This means that banks that adopt technical innovations have relatively better financial advantage than those who do not.

\subsection{Disruptive Innovation Theory}

The disruptive innovation is probably one of the most important innovation theories of the last decade. The core concepts behind it circulated so fast that already in 1998, one year after the publication of the theory, people were using the term without making reference to Harvard professor Clayton Christensen or to his book The Innovator's Dilemma (Harvard Business School Press). The term disruptive innovation as we know it today first appeared in the 1997 best-seller The Innovator's Dilemma. In the book Harvard Business School,Professor Clayton Christensen investigated why some innovations 
that were radical in nature reinforced the incumbent's position in a certain industry, contrary to what previous models (for instance the Henderson - Clark model) would predict. More specifically he analyzed extensively the disk drive industry because it represented the most dynamic, technologically discontinuous and complex industry one could find in our economy. Just consider that the memory capacity packed into a square inch of disk increased by $35 \%$ per year, from 50 kilobytes in 1967 to 1, 7 megabytes in 1973, 12 megabytes in 1981 and 1100 megabytes in 1995.

Disruptive theory is relevant in that it explains the type of technology banks adopt. The banking technology is disruptive because it does away with traditional banking.

\subsection{Schumpeterian Theory of Creative Destruction}

Schumpeter $(1928,1939)$ who saw innovations as perpetual gales of creative destruction that were essential forces driving growth rates in a capitalist system. Schumpeter's thinking evolved over his lifetime to the extent that some scholars have differentiated his early thinking where innovation was largely dependent on exceptional individuals willing to take on exceptional hazards as "an act of will", i.e., entrepreneurs, to his later thinking that recognized the role of large corporations in organizing and supporting innovation. This resulted in his emphasis on the role of oligopolies in innovation which later was falsely viewed as the main contribution of his work. (Freeman, 1994)

Schumpeter (1928) pointed to the discontinuous and disruptive nature of technological change in capitalism that brings the inseparable combination of short-term instability and long-term growth. He was not a technological determinist but recognized the social and organizational forces that played key roles in his cyclical process of industrial change. Schumpeter argued that entrepreneurs, who could be independent inventors or R\&D engineers in large corporations, created the opportunity for new profits with their innovations. In turn, groups of imitators attracted by super-profits would start a wave of investment that would erode the profit margin for the innovation. However, before the economy could equilibrate a new innovation or set of innovations, conceptualized by Schumpeter as Kondratiev cycles, would emerge to begin the business cycle over again.

For all his insight on the role of innovation, Schumpeter still did not really explain the source of innovation. He was able to point to its importance and its role in timing economic cycles but did not address its source. This rather interestingly allowed Keynesian economics to argue that levels of investment were the cause of innovation. It was not until the 1960s that economists begun again to search for the source of innovation. The importance of innovation was highlighted by researchers like Abramovitz (1956) and Solow (1957) who were able to demonstrate how little neoclassical economics was able to explain. Based on data on the United States economy from 1909-49, Solow showed that only 12.5 percent of the increase of per capita output could be traced to increased use of capital. This left a surprisingly large 87.5 percent residual that Solow attributed to technical change.

Romer (1986, 1994) echoes Solow's observation and continued the call for innovation theorists to internalize the process of innovation within their models. To this end, the work on innovation that emerged from the base set by Schumpeter has been concentrated on the creation of innovation and its subsequent diffusion between firms, industries, and regions.

The Schumpeterian Theory is relevant because new technology replaces old technology which is better because new technology is better and adds value to the adopter.

\subsection{Empirical Framework}

Between 2005 and now, Financial Technology had attracted lots of interest, numerous research works has been carried out in the advanced and developing countries. However, a small number of studies have focused on the adoption and the impact of the Financial Technology in Small and Medium Scale Enterprises which is the contribution of this research work.Gerben, Federico and Ferdinand (2016) in their recent work on FinTech with objectives on the innovative power that FinTech brings to financial services, unveiling the reasons why FinTech could be beneficial to micro, small, medium and even large sized companies, and to understand how the huge gap between the traditional banking model and adopting FinTech will be closed since banks physical branches are costly to operate especially in remote areas. In a FinTech case study at Turkey with relatively FinTech solutions, such as SMS and Web based loan applications, shows that FinTech is very effective at serving micro-enterprises compared to larger ones. They concluded that despite the fact that FinTech payment channels are relatively new and their full effect is not yet visible, the analysis suggests that FinTech definitely has its unique characteristics and it can be quite different from the traditional banking channels. FinTech has the potential to impact the whole financial value chain and thus improve financial access for SMEs; FinTech can also lower the cost of SMEs' finance, especially for micro enterprises hiring up to 50 people. For a microfinance enterprise, FinTech are valued by new clients for its simplicity and speed, it is specifically geared towards increasing market share. They further observed that micro entrepreneurs making use of the FinTech channels in their operations are less educated than those interacting through branches.

David (2015) in his quantitative research with various secondary data from Accenture, Bloomberg and other publications, analyzes the success of businesses adopting FinTech, using the LASIC (Low, Margin, Light, Scalable, Innovative and Compliance easy) principles. He postulated that the combination of internet, mobile devices and finance can drive marketbased financial innovation; Fintech has brought about liberalization in the financial system; in some countries, governments have been utilizing mobile money to pay salaries and thus weeding out fraud such as ghost workers (Nigeria), while regulation is not the only factor for the success of FinTech, but low marginal costs and having a socio-cultural appeal to the people. 
Gabriella (2015) African Banker 4th Quarter publication used a case study to analyze the state of FinTech operations in today's financial services and to discover the impediments to the successful implementation of FinTech in service delivery operations. He argues that the more the support for FinTech research, the more solution is generated. He also suggested that partnerships between banks and SMEs will drive financial inclusion as FinTech enables non-card holders to make remote payments for purchase of goods and services. However, the tensions between Central Bank and Mobile Network Operators (MNO) should not be underestimated, as the MNOs are most likely to promote alternative financial channels.

BNY Mellon (2015) in its report on the direction of payment innovations, its objectives are to examine the growing capabilities of FinTech in both consumer/retail and wholesale/corporate payment arenas; to explore how, where and when payments are made as well as who facilitates them; to understand the monumental role of FinTech and the solutions it presents in the business generally. Having conducted series of surveys and extracts from recent publications such as Accenture (2015), its findings show that the payments sector is in the midst of rapid evolution, driven by a sharp uptick in innovation, changing patterns in consumer consumption and a number of industry initiatives and shift in market conditions; Technology innovation focused on SME market has been particularly active (spurred by the impact of financial crisis) giving rise to the emergence and growing popularity of non-traditional forms of finance.

Louis (2014) in his findings discovered that household enterprises (SMEs) provide more than 80\% of employment opportunities in South Africa. Also, he noted that inclusive growth in small business will only be possible if the household enterprise sector which includes small businesses such as farming as well as non-farm enterprises can both expand and increase their productivity.

Oladejo and Adereti (2010) observed that the 1990s witness the proliferation and hyper growth of internet and internet technologies, which together are creating a global and cost-effective platform for business to communicate and conduct commerce. Despite the enormous investment in IT during recent years, demonstrating the effect of such on organizational performance has proven extremely difficult (Mahmood and Mann, 2000). Nigeria is largely a cash-based economy with over 90 percent of funds residing outside the banking sector as against the developed world where the money in circulation is 4 percent in US and 9 percent in U.K as submitted by (Ovia 2002 and 0jo 2004). Whereas the cash-based economy is characterized by the psychology to physically hold and touch cash a culture informed by ignorance, illiteracy, and lack of security consciousness and appreciation of the merit of digital payment.

Public policy needs to provide room for new innovations in the financial sector and to focus regulation only on those components of financial services that entails genuine prudential risk to customers.

Eric and Steven (2002) examined the acceptance and adoption of technology in small business using an exploratory research design in South Africa, they argued that, for e-commerce to be widely accepted by SMEs, there is need for organizational incentives or government support. Their work shows that numerous benefits and inhibitors are accrued to the adoption of technology in small business. While some SMEs perceived the benefits to be irrelevant or not appropriateto their organizations due to lack of knowledge of it. They also noted that most manufacturing businesses in the rural areas lack sophisticated e-Commerce procedure.

A fact confirmed by (Ajayi 2000) and (Ayozie et al. 1997) who postulated that the present small-scale business in Nigeria constitutes over $80 \%$ of all registered companies, occupying positions in agro-based and allied industries, rubberbased, leather shoes industries, chemical, electronics, general merchandising, restaurants, dress making, hair dressing, canechairs, leather products, pomade and toiletries, animal feeds and husbandry, painting etc.

In Germany, Small and Medium Enterprises play a very important part in employment. Almost 60\% of the about 20.7million employees in the economic sectors worked in Small and Medium Enterprises. That is six out of ten persons in employment worked in small and medium - sized enterprises with $18 \%$ of employees in micro enterprises, $22 \%$ in small and $19 \%$ in medium sized enterprises (Kless, 2008). Small and Medium Enterprises generated 46\% of gross value-added and made some $40 \%$ of total gross investment in tangible goods.

In the United Kingdom, Small and Medium Enterprises accounted for over 58\% of all employment with small enterprises accounting for $46.8 \%$, and medium-sized enterprises accounting for $11.7 \%$. They account for more than half $(51.3 \%)$ of the United Kingdom's estimated business turnover of $£ 2400$ billion with small enterprises accounting for $37 \%$, and medium-sized enterprises accounting for 14.3\% (Office of National Statistics, 2005).

In Nigeria, over 97\% of all businesses are Small business and employs less than 100 employees (Ariyo, 2000). Small and Medium Enterprises are known to have contributed significantly to economic development, job creation and sustainable livelihood (NIPC, 2003). The study conducted by the Federal Office of Statistics shows that Small and Medium Enterprises accounted for $50 \%$ employment and contribute $50 \%$ to industrial output.

According to Owualah (1999), small firms make both social and economic contributions to our development process. Entrepreneurs or small and medium enterprises help to raise the level of productivity in the economy by harnessing and utilizing resources more effectively (Inegbenebor, 2006).

Ogundele and Oni (1995) therefore conclude that the Small and Medium Enterprises or the entrepreneurs are the dominant feature in the economies of both developed and developing countries. 


\subsection{Development in Financial Technology}

Innovation is occurring at a rapid rate, with payments-industry enhancements being developed and implemented at a faster pace than ever before, in particular around data management, security, and the move to modular IT.

Cloud-based solutions, for example, are flexible, cost-effective and can be scaled up to accommodate growing demands, enabling businesses to build and adapt their operations more effectively and efficiently. Elsewhere, Application Programming Interfaces (APIs) enable the interaction between two or more online connected services, providing the opportunity to build solutions that integrate and combine different services and data sources. While such processes are available to banks, it is the start-up sector including online payment providers such as PayPal and Stripe that has demonstrated the highest degree of adoption. In fact, new cloud and API technology has been instrumental in enabling the start-up sector to disrupt established players and accelerate change.

In today's truly globalized world where emerging markets have the ability to "leapfrog" their more developed counterparts, and where the transfer of new information is both instantaneous and global, the adoption and impact of new tools and solutions is more rapid and widespread than ever before. Indeed, today's breakneck rate of adoption is itself an enormous driver of change, with many new innovations now achieving mass market penetration at a far faster rate than was ever thought possible, let alone likely.

The almost inconceivable growth in mobile and smart phone usage (in 2014, the number of mobile phones in use surpassed the number of humans on this planet9) is placing digital services in the hands of consumers who previously couldn't be reached, delivering richer, value-added experiences across the globe. Boasting access to cloud-based technology and with consistently-fast mobile signals, smart phones are enabling digital services to be accessed by almost anyone, anywhere, anytime.

Such capabilities are having the most significant impact in emerging markets, particularly those with fast-growing middle-class populations. These previously unbanked populations increasingly require financial services, and mobile phone/device technology allows access to payment solutions without the need for a dedicated physical infrastructure again, speeding up the rate of adoption.

New technology has also significantly improved storage of, access to and interpretation of information and data resulting in significant commercial benefits, yet also the need for greater information protection. Here again, however, new technology is providing an answer, with biometric security leveraging unique identifiers such as fingerprints, facial recognition, iris scanning and voice recognition to provide stronger security, while simultaneously improving the overall user experience.

More recently, proposals have been raised to increase payment and data security by reading and interpreting consumers' spending history. For example, card providers can use data modeling to raise alerts regarding potentially fraudulent activity, and can check a payee's location via their mobile phone's GPS, providing a further data point with which to assess the validity of a transaction.

For payment providers, these and other security initiatives offer the opportunity to push services out to smart phones and other devices (in line with customer demand) without increasing the associated risk.

For the banking industry, perhaps the biggest potential comes from the rise of "big data". Indeed, McKinsey, the consultancy firm, has already identified the banking industry as one of the market sectors that could most benefit from better use of customer and market data. Technology advancements have made it possible to effectively analyses and interpret vast, complex sets of data; uncovering untapped patterns and trends from which new client insights can be gleaned. This "smarter" data management allows banks to create more effective, client-centric solutions that are more aligned to client behaviour and needs. Such capabilities can permit banks to optimize their own internal processes and add significant value to clients through better understanding of their business. Banks can extend these enhanced data management capabilities directly to clients, who can use the insights in a number of ways, including as a means of cost saving through the identification of common errors, for instance.

Certainly, better information management can be a key differentiator, and there is a growing awareness in the business community of the value this data presents, and its significance as a source of competitive advantage if fully leveraged. If banks don't react with urgency and adapt to these developments they are at risk of being overshadowed in the very sector in which they are traditionally renowned. As non-banks continue to introduce a host of new digital capabilities, an element of disruption is emerging within the banking sector and the failure of banks to keep up and offer enhanced client solutions will only exacerbate this.

\section{Methodology}

The concern of this study is the analysis of the impact of Financial Technology on the operations of SMEs in Nigeria. A qualitative research methodology was adopted in analyzing and solving the identified problems. Data collected identified the commonly used financial technology by the SMEs, its impact in their payment operations and the challenges, to obtain valuable conclusions and findings at the end of the research. 


\section{Data Analysis}

\begin{tabular}{|c|c|c|c|}
\hline S/N & MANAGEMENT & NO. OF RESPONDENTS & PERCENTAGE \\
\hline 01 & Senior & 27 & 57 \\
\hline 02 & Middle & 57 & 16 \\
\hline 03 & Junior & 16 & 100 \\
\hline & TOTAL & 100 & 27 \\
\hline
\end{tabular}

Table 1: Office/Business Designation

\section{OFFICE/BUSINESS DESIGNATION}

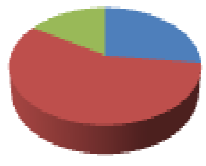

\section{Figure 1}

Table I categorizes the respondents into various levels of management. $27 \%$ represents those in the top management including the owners of the businesses, $57 \%$ consist of those handling the supervisory or manages the business while $16 \%$ are the junior employees of the organizations.

\begin{tabular}{|c|c|c|c|}
\hline S/N & Business & No. of Respondents & Percentage \\
\hline 01 & Retail (Supermarket) & 15 & 15 \\
\hline 02 & Online Merchandise E.g. Ticketing. & 7 & 7 \\
\hline 03 & Fashion and Showbiz & 17 & 17 \\
\hline 04 & Educational Institutions & 4 & 4 \\
\hline 05 & General Merchandise & 57 & 57 \\
\hline & TOTAL & 100 & 100 \\
\hline
\end{tabular}

Table 2: Business Category

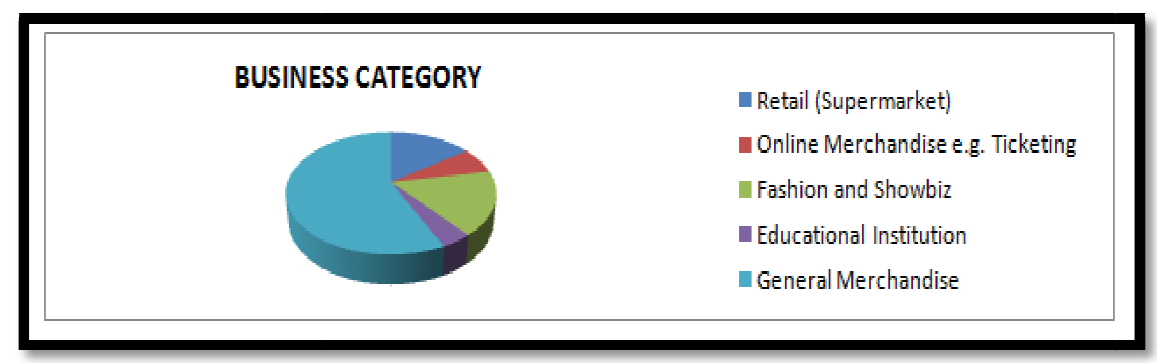

Figure 2

TABLE II shows the spread of small businesses across the four geographical zones of Lagos. Although, the questionnaires were randomly distributed, but the retail stores take $15 \%$, online merchandise $7 \%$, the fashion and entertainment business $17 \%$, education 4\% while Others which involves Agro-allied, furniture, printing centers, trading, aluminum, micro finance firm, church, Travel Consultancy, Hospitality, Law firm, downstream oil \& gas, automobile, ICT, Electronics, pharmaceuticals, food and cosmetics takes $57 \%$.

\begin{tabular}{|c|c|c|c|}
\hline S/N & Channels & No. of Respondents & Percentage \\
\hline 01 & PoS (Point of Sale) & 70 & 54.3 \\
\hline 02 & Mobile (SMS) Payments/Transfer & 35 & 27.1 \\
\hline 03 & Online payments (Bank online portals) & 16 & 12.4 \\
\hline 04 & $\begin{array}{c}\text { Payment Applications (Quick Teller, Remita, } \\
\text { E-tranzact, U-Pay, etc.) }\end{array}$ & 6.7 \\
\hline 05 & Other & 2 & 1.6 \\
\hline & TOTAL & 129 & 100 \\
\hline
\end{tabular}

Table 3: Payment Channels 


\section{PAYMENT CHANNELS}

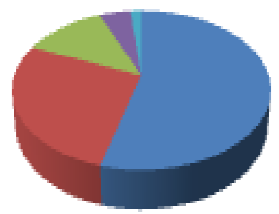

a Pos

- Mobile (SMS) Paments/Transfer

nonline payments (Bank online portals)

Figure 4

TABLE III which represents the various payment options to SMEs' customers. Respondents are allowed to choose more than one payment channel he/she adopts as major option for receiving payments from customers. More than half of the population $54.3 \%$ use PoS as a payment channel, 27.1\% use mobile payment/Transfer payment, while $12.4 \%$ accept online payment. Payment applications such as Quick Teller, Remita, E-tranzact are used by few respondents while only $1.6 \%$ does not use any of the aforementioned option.

\begin{tabular}{|c|c|c|c|}
\hline S/N & Preference & No. of Respondents & Percentage \\
\hline 01 & Yes & 87 & 87 \\
\hline 02 & No & 13 & 13 \\
\hline & TOTAL & 100 & 100 \\
\hline
\end{tabular}

Table 4: Customers Prefer Fintech Channels to Cash Payment?

\section{Customers prefer FinTech Channels to Cash payment?}

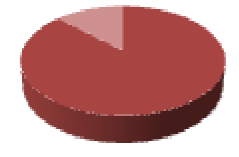

Figure 5

TABLE IV clearly indicates respondents' preference for financial technology as a means of payment. 87\% prefer the use of FinTech channel, while 13\% does not, they rather want cash payment.

\begin{tabular}{|c|c|c|c|}
\hline S/N & Know-How & No. of Respondents & Percentage \\
\hline 01 & Yes & 91 & 91 \\
\hline 02 & No & 9 & 9 \\
\hline & TOTAL & 100 & 100 \\
\hline
\end{tabular}

Table 5: Staff Adequately Knowledgeable in Fintech?

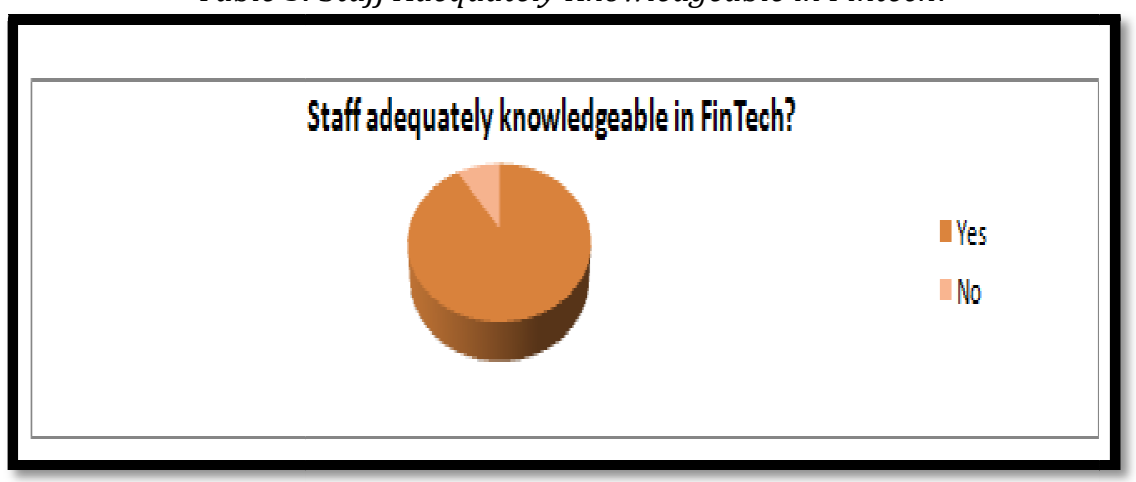

Figure 6 
TABLE V states the level of know-how of FinTech devices by the (staff) i.e. 91\% of the SMEs. Almost all the respondents' staff of $91 \%$ understood the use of the particular FinTech device adopted by the organization. The 9\% (staff) of the respondents are not knowledgeable about the FinTech payment options, reasons can be seen in the next table.

\begin{tabular}{|c|c|c|c|}
\hline S/N & Fintech Improved Your Business? & No. of Respondents & Percentage \\
\hline 01 & Yes & 91 & 91 \\
\hline 02 & No & 9 & 9 \\
\hline & TOTAL & 100 & 100 \\
\hline
\end{tabular}

Table 6: Has Fintech Payment Applications/Solutions Improvedyour Product/Service Delivery?

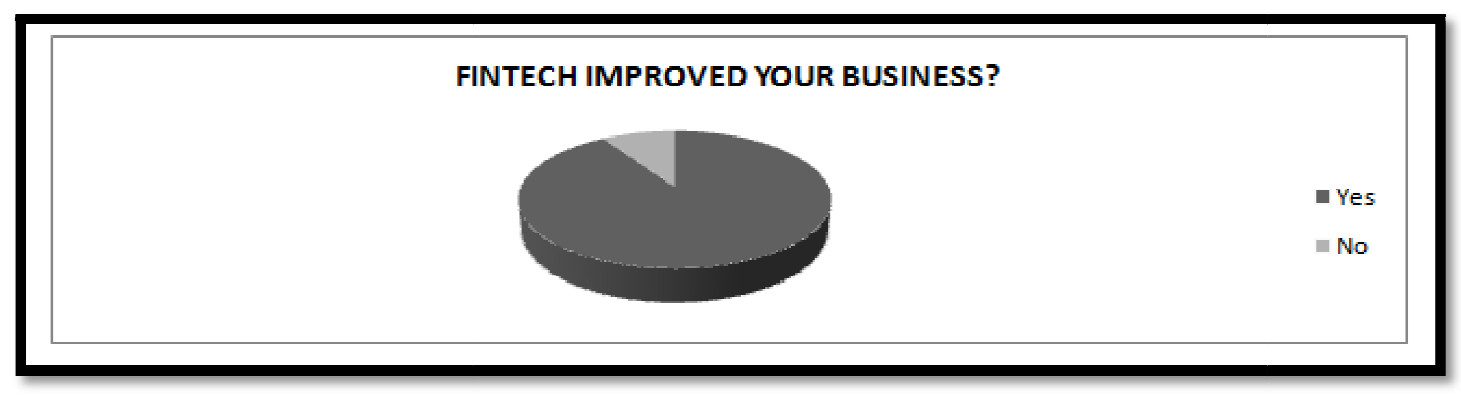

Figure 7

TABLE VI assesses the impact of FinTech channel on respondents' businesses. 91\% confirmed that it has tremendously improved their businesses, such that if a potential customer walks into a store without cash, it does not stop him or her from making his or her purchases. However, 9\% are indifferent about FinTech option, based on the some of the underlisted reasons in Table 4.14

\begin{tabular}{|c|c|c|c|}
\hline S/N & $\begin{array}{c}\text { Has Fintech Increased Your Market } \\
\text { Share/Profit? }\end{array}$ & No. of Respondents & Percentage \\
\hline 01 & Yes & 93 & 93 \\
\hline 02 & No & 7 & 7 \\
\hline & TOTAL & 100 & 100 \\
\hline
\end{tabular}

Table 7: Has Fintech Increased Your Market Share and Profit?

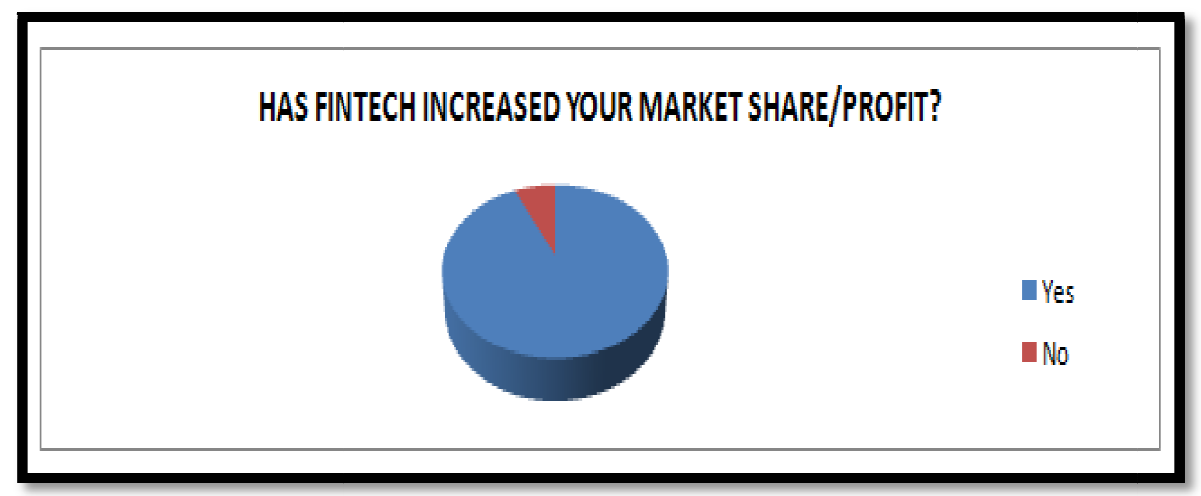

Figure 8

TABLE VII indicates respondents' opinion with respect to the contribution of FinTech to the market share/profit. 93\% which constitute the majority of the respondents, experiences increment in market share/profit since customers now have numerous payment options. But 7\% disagreed with that, they claimed that their businesses remained stagnant due to some factors such as costs of maintenance and high service charges.

\begin{tabular}{|c|c|c|c|}
\hline S/N & $\begin{array}{c}\text { Fintech Has Reduced Cost of } \\
\text { Operations }\end{array}$ & No. of Respondents & Percentage \\
\hline 01 & Yes & 74 & 74 \\
\hline 02 & No & 26 & 26 \\
\hline & TOTAL & 100 & 100 \\
\hline
\end{tabular}

Table 8: Has Fintech Applications/Solutions Reduce the Cost of Operations in Your Organization? 


\section{FINTECH HAS REDUCED COST OF OPERATIONS}

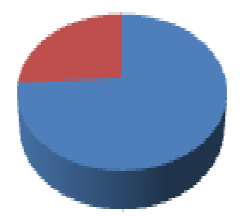

Yes

No

Figure 9

Generally, every individual and business entity wants effective and efficient service delivery just as the FinTech aims to provide. To some respondents (74\%), it was a joyous innovation in their business operations, as they now have no reason to restrict anyone from making huge purchases without cash and payment is made remotely. Also, business owners do not have to leave their offices/stores to transact business with suppliers, most transactions are carried out under one roof without any movement, cutting out transportation cost, energy, stress and time. However, $26 \%$ of the respondents seem not to appreciate the benefits of FinTech irrespective of its merits. Reasons for this are outlined below:

\section{Hypothesis Testing}

\subsection{Hypothesis I}

- Ho: There is no significant relationship between FinTech and Improved service delivery.

- Hi: There is significant relationship between FinTech and Improved service delivery.

The researcher observed the relationship between FinTech and Improved service delivery of the SMEs.

\begin{tabular}{|c|c|c|c|}
\hline Questions & Yes & No & Total \\
\hline $\begin{array}{c}\text { 12. Does your company have enough contents on FinTech payment } \\
\text { channels on its marketing communication programs and publication and } \\
\text { adverts? }\end{array}$ & 73 & 27 & 100 \\
\hline $\begin{array}{c}\text { 13. Has FinTech payment application and solutions improved your } \\
\text { service/product delivery to customers? }\end{array}$ & 91 & 9 & 100 \\
\hline $\begin{array}{c}\text { Total } \\
\text { Average (Expected) }\end{array}$ & 164 & 36 & 200 \\
\hline
\end{tabular}

Table 9

We have to compute the statistic $\mathrm{X}^{2}{ }_{\Sigma}\left(\mathrm{O}_{\mathrm{i}}-\mathrm{e}_{\mathrm{j}}\right)$ in order to investigate the agreement between

$e_{j}$ observed $\left(\mathrm{O}_{\mathrm{i}}\right)$ and expected $\left(\mathrm{e}_{\mathrm{j}}\right)$ frequencies in the $\mathrm{jth}$ cell.

\begin{tabular}{|c|c|c|c|c|c|c|}
\hline Questions & Options & 0 & $\mathbf{E}$ & O-E & $(0-E)^{2}$ & $\frac{(\mathrm{O}-\mathrm{E})^{2}}{\mathrm{E}}$ \\
\hline \multirow{2}{*}{$\begin{array}{l}\text { 12. Does your company have enough contents on } \\
\text { FinTech payment channels on its marketing } \\
\text { communication programs and publication and } \\
\text { adverts? }\end{array}$} & Yes & 73 & 82 & -9 & 81 & 0.99 \\
\hline & No & 27 & 18 & 9 & 81 & 4.5 \\
\hline \multirow{2}{*}{$\begin{array}{l}\text { 13. Has FinTech payment application and } \\
\text { solutions improved your service/product } \\
\text { delivery to customers? }\end{array}$} & Yes & 91 & 82 & 9 & 81 & 0.99 \\
\hline & No & 9 & 18 & -9 & 81 & 4.5 \\
\hline Total & & & & & & 10.98 \\
\hline
\end{tabular}

Table 10

$\Sigma(\mathrm{O}-\mathrm{E})^{2}=10.98$

$\mathrm{E}_{\mathrm{j}}$ 
Degree of Freedom $=(\mathrm{r}-1)(\mathrm{c}-1)$, where $\mathrm{r}=$ row; $\mathrm{c}=$ column

Therefore, $(\mathrm{r}-1)(\mathrm{c}-1)=(2-1)(2-1)=1 \times 1=1$

Hence, the critical value $\mathrm{X}^{2} 0.95$ for 1 degree of freedom is 3.84

(i.e. $95 \%$ or $0.05 \%$ level of significance), the table value $\mathrm{X}^{2}=3.84$

Compare:

Calculated $\mathrm{X}^{2}=10.98$

Tabulated $\mathrm{X}^{2}=3.84$

\subsection{Decision}

Since the calculated $\mathrm{X}^{2}$ value is greater than the tabulated value, we reject Ho and accept Hi Hence, there is significant relationship between FinTech and Improved service delivery.

\section{Conclusion}

FinTech has recently captured a lot of public attention for a good reason. This reason can be centered on EASE, SPEED and CONVENIENCE of service delivery. If given the right environment, FinTech provides many micro and macro-economic benefits, such as the greater availability of data, exponential growth in computing power allowing the analysis of ever larger data sets, broader access to and the decreasing cost of goods and services, increasing disintermediation and re-intermediation, and demographic and generational changes and holds great potential for financial and digital inclusion. FinTech could become one of the most powerful tools to support small businesses and thus stimulate sustainable economic growth. With the integration of Financial Regulators into the entire FinTech ecosystem, small businesses can participate in many solutions that were previously only available to larger companies. It is clear from this study that, taking together, the changes already underway as a result of Fintech are substantial, in certain cases leading to disintermediation and re-intermediation, and in other cases testing the boundaries of full disruption through the use of technology. We hope this research work may be useful to a diverse readership to form a better understanding of the transformation that is already underway and to harness the bountiful opportunities that comes with FinTech. As more FinTech solutions are created, more job opportunities are also available, such as FinTech manager, e-Fraud expert, data managers, online merchants, e-enforcement agencies, back-up officers, application developer and managers, e-marketer, transaction managers, card transaction managers, mobile transaction managers, pay-point agents, etc. so that each may be prepared for the benefits and opportunities, as well as the risks and challenges accrued.

\section{References}

i. Abramovitz, M. (1956). Resource and Output Trends in the United States since 1870.

ii. Accenture (2015), "The Future of Fintech and Banking: Digitally disrupted or reimagined?"http://www.fintechinnovationlablondon.net/media/730274/Accenture-The-Future-of-Fintech-andBanking-digitallydisrupted-or-reima-.pdf

iii. Ajayi G. O. (2000) Entrepreneurship Development in Nigeria.Ajayi Publishing, Abeokuta, Nigeria.

iv. Ayozie D. O. et all (1997), Principles and Practice of Marketing for Nigerian Students and Managers. Kinsbond Publishers Ilaro, Ogun State, Nigeria.

v. Ariyo D (2000). "Small firms are the backbone of the Nigeria economy", Africa Economic Analysis, Africa Business Information Services, Bridgnorth.

vi. Bank of New York Mellon (2015), Global Payments 2020: Transformation and Convergence. White paper. www.bnymellon.com

vii. Clayton M. Christensen (1997), “The Innovation Dilemma: When New Technologies cause great firms to fail. Harvard Business School Press.

viii. David LEE KuoChuen (2015), Emergence of FinTech and the LASIC Principles, Quantitative Finance, SimKee Boon Institute for Financial Economics, Singapore Management University

ix. Eric Cloete, Steven Courtney, Julia Fintz (2002). Small Businesses' Acceptance and Adoption of e-Commerce in the Western-Cape Province of South Africa.Department of Information Systems, University of Cape Town, South Africa.http://www.ejisdc.org

x. Evangeline W. Wachira (2013), The effect of Technological Innovation on the financial performance of Commercial Banks in Kenya, D61/62702/2010 - Masters Research Project submitted to the School of Business Administration, University of Nairobi.

xi. Freeman, C. 1994. The economics of technical change - a critical survey. Cambridge Journal of Economics. Vol 18.

xii. Gabriella Mulligan (2015), “African banks and fintech startups -an ideal match?”African Banker 4th Quarter 2015, Pg 33-35.

xiii. GerbenHieminga, Federico Lande, Ferdinand Nijboer (2016), FinTech for micro, small and medium sized enterprises: Creating jobs at the bottom of the pyramid through financial and digital innovation. Authors ING (Int'l Netherlands Group) Economics Department 
xiv. Inegbenebor AU (2006). You can be an Entrepreneur: The Fundamantals of Entrepreneurship, Lagos: Malthouse Press Limited, pp 1- 14, 1st Edition.

xv. Kombo DK, Tromp DLA (2009). Proposal and Thesis Writing.An Introduction.Paulines Publications Africa, Don Bosco Printing Press, Nairobi, Kenya.

xvi. Louis Kasekende (2014). "What Role Does Financial Inclusion Play in the Policy Agenda for Inclusive Growth in SubSaharan Africa?" Development (2014), 57 (3-4), (481-487).

xvii. Mahmood, M. Adam and Mann Gary. J (2000); Special Issue: Impact of Information Technology on Organizational Performance Vol. 16, No. 4 Pp 3-10.

xviii. Matthew A. Zook (1997), Technological Innovation and Theories of Regional Development. Inside Field Statement, Department of City and Regional Planning, University of California-Berkeley. http://www.doc88.com/p3488702207842.html

xix. Nigeria Investment Promotion Commission Information Booklet (2003): Overview of Small and Medium Scale Enterprises in Nigeria.

xx. Office for National Statistics (2005), Statistical Press Release URN 05/92

xxi. Ogundele OJK, Oni JO (1995). The controversial dimension of organizational effectiveness with specific reference to a sample of SME in Nigeria. In A. T. Ojo (ed) Management of Small and Medium Enterprises in Nigeria pp. 22 - 29. Ikeja: Pumark Nigeria Ltd.

xxii. Oladejo, M. O and Adereti, A. S. (2010). "The impact of Information Technology on the Performance of Micro finance Institutions in Nigeria, Journal of Economic Development and Managerial Studies, Vol.1 No.1, April 2010 edition. www.icidr.org

xxiii. Ovia Jim (2002), "Payment System and Financial Innovations” A paper presented at the Annual Policy Conference, Nov. 2002.

xxiv. Owualah, S. I. (1999): Entrepreneurship in Small Business Firms, Lagos: G-MAG Investment Ltd (Educational publishers), 1st Edition.

xxv. $\quad$ Rogers, E.M. (1995). Diffusion of Innovations (4 ed.). New York: The Free press.

xxvi. Romer Paul M. (1986), "Increasing Returns and Long-Run Growth” Journal of Political Economy, October 1986, 94:5, 1002-37.

xxvii. Solow Robert (1957), “Technical Change and the Aggregate Production Function” Review of Economics and Statistics, August 1957, 39, 312-20

xxviii. Schumpeter JA (1928), “The instability of capitalism”. Econ J. 38:361-86

xxix. Schumpeter JA (1939), "Business cycles: a theoretical, historical and statistical analysis of the capitalist process". McGraw-Hill, New York. 